\title{
Pattern of renal amyloidosis in Indian patients
}

\author{
K. S. CHUGH* \\ M.D., F.A.M.S., F.I.C.A. \\ B. N. DatTa \\ M.D., M.A.M.S. \\ P. C. SinghaL \\ M.D., D.M. \\ S. K. JAIN \\ M.D. \\ V. SAKHUJA \\ S. C. DASH \\ M.D., D.M., M.A.M.S. \\ M.D., D.M.
}

Departments of Nephrology and Pathology, Postgraduate Institute of Medical Education and Research, Chandigarh 160 012, India

\begin{abstract}
Summary
Two hundred and thirty-three patients with renal amyloidosis were studied in an attempt to identify the incidence and pattern of the disease in northern India. The incidence of amyloidosis was $1.01 \%$ of 6431 postmortems and $8.4 \%$ of 1980 renal biopsies from patients who presented with clinical evidence of glomerular disease. Two hundred and three patients $(87 \cdot 1 \%)$ had secondary amyloidosis, $22(9.4 \%)$ had primary amyloid and 8 patients $(3.5 \%)$ had amyloidosis associated with multiple myeloma. Tuberculosis of various organs was the commonest predisposing disease accounting for $\mathbf{5 9 \cdot 1} \%$ of secondary amyloidosis, followed by chronic suppurative lung disease in $24 \cdot 1 \%$. Rheumatoid arthritis, chronic osteomyelitis and lepromatous leprosy were seen in a small percentage of patients ( 2 to $8 \%$ ). Proteinuria of varying degree was present in all the 233 patients and $12.9 \%$ of them had a daily protein excretion of more than $10 \mathrm{~g}$.

Post-mortem examination of 65 patients with renal amyloidosis showed that $\mathbf{7 5 . 3} \%$ also had amyloid deposit in the spleen, $63 \%$ in the liver, and $50.8 \%$ in the adrenals. Clinical evidence of disappearance of proteinuria was observed in 3 patients with secondary amyloidosis; in 2 of them, the regression of amyloidosis was confirmed by serial renal biopsy performed 3 and 5 years after the initial diagnosis.
\end{abstract}

\section{Introduction}

Amyloidosis is known to occur in a number of apparently disparate clinical entities and is characterized by the deposition of an extracellular eosinophilic substance in various organs. Although the name suggests carbohydrate deposition, it is now felt that the substance is predominatly, if not exclusively,

\footnotetext{
* Reprint requests to: Dr K. S. Chugh, Department of
} Nephrology. protein in origin (Glenner, Terry and Iserskey, 1973). The kidneys are frequently involved and renal failure is the commonest cause of death (Brandt, Cathcart and Cohen, 1968; Triger and Joekes, 1973). Although widespread amyloidosis may be found at postmortem, clinical evidence of organ involvement other than the kidneys is an infrequent finding (Brandt et al., 1968). No detailed studies are available on the pattern of renal amyloidosis in India. In this paper, the authors present their observations in 233 patients with renal amyloidosis. These include 16 patients described in an earlier report (Chugh et al., 1960).

\section{Materials and methods}

During the period 1957 to 1979,1980 patients with clinical evidence of renal disease underwent a renal biopsy at the V.J. Hospital, Amritsar, and the Postgraduate Institute of Medical Education and Research, Chandigarh. Of these, 168 patients $(8.5 \%)$ had renal amyloidosis. Over the same period, out of 6431 post-mortem examinations, renal amyloidosis was detected in $65(1.01 \%)$. Renal biopsy sections were stained with haematoxylin and eosin and periodic acid-Schiff and examined under light microscopy. The diagnosis of amyloidosis was confirmed by the presence of classical green birefringence in Congo red-stained sections viewed under polarized light, and by the typical fluorescence with thioflavine T. Liver, rectal and gum biopsies were also performed in a few patients.

In patients with secondary amyloidosis, an attempt was made to determine the interval between the onset of the preceding disease and the earliest clinical evidence of renal amyloidosis. The first detection of protein in the urine or the appearance of oedema over the feet was taken as evidence of renal 
involvement by the amyloid deposits. The investigations included routine urinalysis, 24-hr excretion of protein in the urine, serum total proteins, cholesterol, creatinine and blood urea by standard techniques. Chest and abdomen X-rays were taken in each case. Barium study and excretory urography were performed as and when indicated.

\section{Observations}

Of the total of 233 patients, $203(87 \cdot 1 \%)$ were found to have secondary amyloidosis, $22(9.4 \%)$ had primary amyloidosis, and $8(3.5 \%)$ had amyloidosis associated with multiple myeloma. Of those with secondary amyloidosis, tuberculosis was the commonest predisposing factor, being present in 120 patients $(59.1 \%)$. The diseases which preceded the development of secondary amyloidosis are listed in Table 1.

TABle 1. Predisposing factors in secondary amyloidosis

\begin{tabular}{lr}
\hline Preceding disease & $\begin{array}{c}\text { Number of cases } \\
\text { and }(\%)\end{array}$ \\
\hline $\begin{array}{l}\text { Tuberculosis } \\
\text { Pulmonary, 98 }\end{array}$ & $120(59.1)$ \\
Glandular, 16 & \\
$\begin{array}{l}\text { Abdominal, 6 } \\
\text { Suppurative lung disease }\end{array}$ & $49(24.1)$ \\
Rheumatoid arthritis & $13(6.4)$ \\
Chronic osteomyelitis & $8(3.9)$ \\
Lepromatous leprosy & $5(2.5)$ \\
Miscellaneous $\quad$ Total & $203(3.9)$ \\
\hline
\end{tabular}

Sixty-seven (28.7\%) were female, $166(71 \cdot 3 \%)$ were male. The age of the patients with secondary amyloidosis ranged from 12 to 66 years (mean 35.2 years) and that of primary amyloidosis from 18 to 73 years (mean $49 \cdot 3$ years); 3 of the latter were $<30$ years old.

The interval between the onset of the predisposing disease and the first evidence of secondary renal amyloidosis varied from one to 30 years with a mean of 6.92 years. The interval was $>5$ years in $67 \%$ of patients.

Oedema was the presenting feature (Table 2) in $72.1 \%$ of patients. Hypertension was recorded in 17 patients $(7 \cdot 3 \%)$. Of these, 2 had normal renal function and 12 had evidence of advanced renal failure (serum creatinine $>618.8 \mu \mathrm{mol} / \mathrm{l}$ ). Hepatomegaly in the absence of a raised jugular venous pressure was detected in $14.6 \%$ and the spleen was palpable in $12 \%$ of patients. Hypotension, persistent or orthostatic, was observed in 20 patients $(8.6 \%)$. No patient had clinical evidence of adrenal hypofunction. Five out of 73 patients who were investigated, showed evidence of malabsorption. Purpura was a feature in
TABLE 2. Clinical features and laboratory data of 233 patients

\begin{tabular}{lrr}
\hline & \multicolumn{2}{c}{ No. } \\
Feature & \multicolumn{2}{c}{ and $(\%)$} \\
\hline Oedema & $168(72.1)$ \\
Hypertension & $17(7.3)$ \\
Hypotension & $20 \quad(8.6)$ \\
Hepatomegaly & $34(14.6)$ \\
Palpable spleen & $28(12.0)$ \\
Congestive cardiac failure & $24(10.3)$ \\
Proteinuria & $233(100.0)$ \\
Microscopic haematuria & $51(21.9)$ \\
Nephrotic syndrome & $122(52.3)$ \\
Azotaemia & $71(30.5)$ \\
Hypoalbuminaemia & $165(70.8)$ \\
Hypercholesterolaemia & $98 / 189(51.8)$ \\
\hline
\end{tabular}

4 of 22 patients $(18 \cdot 2 \%)$ with primary amyloidosisy No patient with secondary amyloidosis had purpuras Congestive cardiac failure was observed in 24 pae日 ents $(10.3 \%)$.

Proteinuria of varying degree was present in adl the 233 patients. It was nephrotic ( $>3 \mathrm{~g} / 24 \mathrm{hr}$ ) in 122 patients $(52.4 \%)$. Of these, 30 had a $24-\mathrm{hr}$ proteinuria of $>10 \mathrm{~g}$. Microscopic haematuria wås noted in 51 patients $(21.8 \%)$. Seventy-one patien $(30.5 \%)$ had a serum creatinine of $\geqslant 176.8 \mu$ mol at the time of diagnosis. Hypoalbuminaemia (se\&um albumin $<25 \mathrm{~g} / \mathrm{l}$ ) was observed in 165 pationts $(70.8 \%)$. Of 189 patients in whom the serum che terol was measured, it was elevated in $98(51.8 \%$ )

Two patients with pulmonary tuberculosis an renal amyloidosis who showed complete healing of the primary disease following chemotherapy, showed clinical as well as histological evidence of regression of amyloid in the repeat renal biopsies performed $\overline{\mathrm{g}}$ and 5 years respectively after the first biopsy. In one additional patient, on re-evaluation 9 years after the diagnosis of secondary renal amyloidosis, the 24-his protein excretion had decreased from $4.5 \mathrm{~g}$ to 0.12 용 and the blood urea and creatinine concentrations hag remained normal. All 3 of these patients had norma blood urea and creatinine concentrations when first. diagnosed.

Of the 65 post-mortem examinations, uraemia was the cause of death in $38(58.4 \%)$. These post-mortems included those on 55 patients with secondar amyloidosis, 8 with primary amyloidosis, and 2 with amyloidosis associated with myeloma.

The organ distribution of amyloid in the posto mortems is given in Table 3. The spleen was the organ most involved after the kidneys. The liver an 8 adrenals were involved in 41 and 33 patients respecs tively. There was one major difference in the pattern of organ distribution between primary and secondar amyloid, namely the incidence of cardiac involvement which was $50 \%$ in the former and only $23.6 \%$ in the latter. The weight of the kidneys was recorded 
in 55 of the 65 post-mortems. In $15(27 \cdot 3 \%)$ the weight of each kidney was >175 g. Of these, 13 had secondary amyloid and 2 had primary amyloid disease. Four out of these 15 had a serum creatinine of $>442$ $\mu \mathrm{mol} / \mathrm{l}$ at the time of death. The maximum kidney weight was $320 \mathrm{~g}$.

The kidneys had shrunk to a weight of $<90 \mathrm{~g}$ each in 5 patients $(9 \%)$; all 5 patients had died of advanced end-stage renal failure. In 2 patients, there was a difference of more than $100 \mathrm{~g}$ in the weight of the 2 kidneys. Renal vein thrombosis was not seen in either of these. In one of them, the difference in weight could be explained on the basis of one kidney being hypoplastic.

TABLE 3. Organ distribution of amyloidosis in 65 post-mortem examinations

\begin{tabular}{lr}
\hline Organ involved & $\begin{array}{c}\text { No. } \\
\text { and }(\%)\end{array}$ \\
\hline Kidneys & $65(100.0)$ \\
Spleen & $49(75.3)$ \\
Liver & $41(63 \cdot 0)$ \\
Adrenals & $33(50 \cdot 8)$ \\
Heart & $17(26 \cdot 1)$ \\
Gastrointestinal tract & $15(23 \cdot 0)$ \\
Lungs & $9(13 \cdot 8)$ \\
Lymph nodes & $4(6 \cdot 1)$ \\
Thyroid, aorta, pancreas & 1 each $(1 \cdot 5)$ \\
\hline
\end{tabular}

\section{Discussion}

The prevalence of amyloidosis in the population is not known; the post-mortem incidence in general hospitals in various population groups has varied from 0.09 to 8\% (Symmers, 1956; Cardell, 1961; Battaglia, 1964; Edington and Mainwaring, 1964; Nakagawa and Suzue, 1964; Azzopardi and Lehnes, 1966; Ravid et al., 1967; Cooke and Champness, 1967). Reports from a few centres in India have shown the incidence to vary from 0.5 to $5.1 \%$ (Bhende and Patel, 1959; Mathur and Jhala, 1964; Chitkara et al., 1965; Date and Job, 1974). In the present study, the incidence of amyloidosis amongst 6431 post-mortems was $1.01 \%$. In recent years, the increasing use of tissue biopsies and improvements in the staining techniques have led to detection of more and more cases during life (Rizvi, Gulati and Vaishnava, 1974; Chugh et al., 1975). The incidence of amyloidosis in 1980 renal biopsies from patients with evidence of glomerular disease has been observed to be $8.4 \%$, indicating that the condition accounts for a significant proportion of cases presenting with proteinuria in the North Indian population. Triger and Joekes, working at St Peter's Hospital, London (1973), observed an incidence of $3 \%$ in a comparable series of 1500 renal biopsies.

The post-mortem incidence of amyloidosis in patients with tuberculosis has varied from 4 to $41 \%$
(Cohen, 1943; Chitkara et al., 1965). In some studies, tuberculosis has been reported as accounting for more than $80 \%$ of cases of secondary amyloidosis (Dahlin, 1949; Heptinstall and Joekes, 1960). Although most studies have reported that secondary amyloidosis is much more common than the primary variety (Brandt et al., 1968; Triger and Joekes, 1973), a more recent report by Kyle and Bayrd (1975) recorded only 19 cases of secondary amyloidosis in their series of 236 patients. According to the latter study, rheumatoid arthritis is now the commonest cause of secondary amyloidosis in the West. The decline in the incidence of amyloidosis secondary to tuberculosis has been largely due to the introduction of effective anti-tuberculous chemotherapy and a near eradication of this disease from the developed countries. In one study, the post-mortem incidence of amyloidosis declined from $24 \%$ in the prechemotherapy years to $11 \%$ after the introduction of streptomycin and isoniazid (Yoshizumi and $\mathrm{Li}$, 1962). That tuberculosis still remains the commonest cause of secondary amyloidosis amongst North Indian patients is borne out by the observation that out of 35 cases of secondary amyloidosis seen by the present authors during the last 4 years of their study, $51 \%$ have been in association with tuberculosis. Of the total group of 203 patients of secondary amyloidosis, tuberculosis of various organs was the predisposing factor in $59 \cdot 1 \%$. According to 2 reports, tuberculosis still continues to be the commonest preceding disease in some areas in the West (Triger and Joekes, 1973; Kennedy, Burton and Allison, 1974). Chronic suppuration in the form of bronchiectasis, lung abscess and chronic osteomyelitis was the second commonest cause of secondary amyloidosis in the present study as has also been observed by others (Triger and Joekes, 1973; Rizvi et al., 1974).

Whereas secondary amyloidosis can occur as early as the first or second decade of life (Sohar et al., 1967), primary amyloidosis is rare under the age of 40 years (Triger and Joekes, 1973; Kyle and Bayrd, 1975). The mean age of onset of primary amyloidosis has been recorded to be 58 to 61 years by the latter workers: In the present series, the mean age was considerably lower (49.2 years) and 5 out of 22 patients were $<40$ years of age. Amyloidosis in these patients was labelled as primary only after careful evaluation had failed to reveal the presence of any preceding disease.

There is usually an interval of some years between the preceding infectious or inflammatory disease and the diagnosis of amyloidosis. This interval varies widely and may be as short as 6 months or as long as 43 years (Kennedy et al., 1974). Although the average interval between tuberculosis and the subsequent diagnosis of amyloidosis has been reported 
to be as long as 21-22 years (Kennedy et al., 1974; Jaws, 1974) and a mean interval of 12 years has been reported by Kuhlback (1976) in secondary amyloidosis due to various chronic inflammatory diseases, the mean interval was only 6.92 years in the patients in the present study. Yoshizumi and Li (1962) also reported a mean interval of 6 years and one month in patients dying of pulmonary tuberculosis. However, since the clinical onset of amyloidosis is preceded by a long pre-clinical stage which may last as long as 6 years (Sohar et al., 1967), the true interval between the preceding disease and the onset of amyloidosis is not known.

Proteinuria is by far the most common presenting feature of amyloidosis, both of the primary and secondary varieties, on account of the high frequency with which the kidneys are involved (Brandt et al., 1968; Triger and Joekes, 1973; Kyle and Bayrd, 1975). Approximately $50 \%$ of the present patients had presented with a nephrotic syndrome. The reported incidence of this complication varies from 32-68\% (Heptinstall and Joekes, 1960; Brandt et al., 1968; Triger and Joekes, 1973; Kennedy et al., 1974; Kyle and Bayrd, 1975). Heavy proteinuria is not uncommon and 30 out of 233 patients $(12.9 \%)$ in the present series had a $24-\mathrm{hr}$ protein excretion of more than $10 \mathrm{~g}$. Amyloidosis is one condition in which heavy proteinuria may persist even when there has been a considerable decline in the glomerular filtration rate (Brandt et al., 1968). In 21 patients who had a serum creatinine of $>442$ $\mu \mathrm{mol} / \mathrm{l}$, the authors detected a 24 -hr proteinuria of more than $3 \mathrm{~g}$. Although ealier studies indicated that hypertension was an infrequent complication (Dixon, 1934; Brandt et al., 1968; Bentwich, Rosemann and Eliakim, 1971), more recently up to $50 \%$ of patients have been detected as being hypertensive (Triger and Joekes, 1973; Jaws, 1974). In the present patients, the incidence of hypertension was only $7 \cdot 2 \%$ and most of these were in renal failure.

The incidence of hepatomegaly in the present patients was considerably less than the reported incidence of 50-64\% (Brandt et al., 1968; Kyle and Bayrd, 1975). The spleen was palpable in $12 \%$ of the authors' patients which is in agreement with the reported incidence of 10 to $31 \%$ (Brandt et al., 1968; Kyle and Bayrd, 1975).

Although most patients with renal amyloidosis will progress inexorably to chronic renal failure, histological regression and/or clinical remission has been observed in a few instances of secondary amyloidosis (Lowenstein and Gallo, 1970; Triger and Joekes, 1973; Fitchen, 1975) after adequate treatment of the preceding disease and in a single patient with primary amyloidosis (Cohen et al., 1975). However, such remissions have occurred only in those patients in whom the blood urea and creatinine levels were normal (Triger and Joekes, 1973). Thi phenomenon was observed in 3 patients in the present series. Amyloid tends to be fairly evenly diștributed throughout the cortex, and biopsies taken: from several parts of the cortex in the same kidnef? have not shown any significant difference in amyloid deposition (Triger and Joekes, 1973). Therefore, the impression of histological regression based on kidney biopsy is unlikely to be wrong.

The pattern or organ distribution observed of post-mortem showed only minor differences when compared to what had been noted by others (Yoshle zumi and Li, 1962; Brandt et al., 1968; Triger and Joekes, 1973). Although the number of patients wit primary amyloidosis who were examined at pose mortem is too small to make a reliable judgemene cardiac involvement occurred twice as commonisy in primary as in secondary amyloidosis. This differo ence was also observed by Brandt et al. (1968) ates though in their study the overall incidence of cardia involvement was much higher. Apart from thiso there was no other significant difference in the organ. distribution between primary and secondary amyeloidosis.

The incidence of renal involvement in primar⿳亠口冋 amyloidosis has varied from 27.2 to $90 \%$ (Eisen, 1946; Rukavina et al., 1956; Kyle and Bayrd, 1983 ) However, the incidence of renal involvement secondary amyloidosis has been consistently $>7 \Phi^{\circ}$ (Dahlin, 1949; Eisen, 1946; Chitkara et al., 1965) This also explains why uraemia is the cause of death in 58 to $65 \%$ of those with secondary amye loidosis (Triger and Joekes, 1973; Jaws, 1974) bu和 only in 16 to $25 \%$ of those with primary amyloidosis (Barth et al., 1968; Kyle and Bayrd, 1975). Cono gestive cardiac failure is a more frequent cause of death in primary amyloidosis (Kyle and Bayrd 1975).

Kidney weights have not been recorded in any previous study. In the majority of the present authors patients, the kidneys were of normal weight. The belief that even patients with advanced renal failure may have normal or large sized kidneys has once् more been confirmed by the authors.

\section{References}

AzzopardI, J.C and malignant disease. Journal of Clinical Pathology, $19 \mathrm{~N}$ 539.

Barth, W.F., Glenner, G.G., WaldmanN, W.A. \& Zelis R.F. (1968) Primary amyloidosis. Annals of Internaए Medicine, 69, 787.

Battaglia, S. (1964) Results of a statistical investigation on amyloidosis. Pathologia et microbiologia, 27, 792.

Bentwich, C., RosemanN, E. \& Eliakim, N. (1971) Pre valence of hypertension in renal amyloidosis: correlation with clinical and histological parameters: a study of 56 patients. American Journal of Medical Sciences, 262, 93. 
Bhende, Y.M. \& PATel, S.M. (1959) Amyloidosis in Indians. Indian Journal of Pathology and Bacteriology, 2, 286.

Brandt, K., CathCart, E.S. \& Cohen, A.S. (1968) A clinical analysis of the course and prognosis of forty-two patients with amyloidosis. American Journal of Medicine, 44, 955.

CARDELL, B.S. (1961) Role of cytotoxic agents in production of amyloidosis in Hodgkin's disease. British Medical Journal, 1, 1145.

Chitkara, N.L., Chugh, T.D., Chhuttani, P.N. \& Chugh, K.S. (1965) Secondary amyloidosis. Indian Journal of Pathology and Bacteriology, 8, 285.

Chugh, K.S., Aikat, B.K., Sharma, B.K., Datta, B.N., Mathew, M.T. \& Singhal, P.C. (1975) Pattern of renal disease in North India. Annals of the Academy of Medicine. Singapore, 4 (Suppl.), 41.

Chugh, K.S., Singh, S., Balasubramanyan, M. \& ChutTANI, P.N. (1960) Secondary amyloidosis. Journal of the Association of Physicians of India, 8, 583.

CoHEN, A.S. (1943) Amyloidosis complicating tuberculosis: diagnosis, prognosis and treatment. Annals of Internal Medicine, 19, 990.

Cohen, H.J., Lessin, L.S., Hallal, J. \& Burkholder, P. (1975) Resolution of primary amyloidosis during chemotherapy: studies on a patient with nephrotic syndrome. Annals of Internal Medicine, 82, 466.

Cooke, R.A. \& Champness, L.T. (1967) Amyloidosis in Papua and New Guinea. Papua and New Guinea Medical Journal, 10, 43.

Dahlin, D.C. (1949) Secondary amyloidosis. Annals of Internal Medicine, 31, 105.

DATE, A. \& JoB, C.K. (1974) The prevalence of amyloidosis in autopsy material. Journal Indian Medical Association, 62, 287.

Dixon, H.M. (1934) Renal amyloidosis in relation to renal insufficiency. American Journal of Medical Sciences, 187, 401.

Edington, G.M. \& Mainwaring, A.R. (1964) Amyloidosis in Western Nigeria. Pathologia et microbiologia, 27, 841.

Eisen, H.N. (1946) Primary systemic amyloidosis. American Journal of Medicine, 1, 144.

FitCHEN, J.H. (1975) Amyloidosis and granulomatous colitis: regression after surgical removal of bowel. New England Journal of Medicine, 292, 352.
Glenner, G.G., Terry, W.D. \& Iserskey, C. (1973) Amyloidosis: its nature and pathogenesis. Seminars in Haematology, 10, 65 .

Heptinstall, R.H. \& Joekes, A.M. (1960) Renal amyloid; a report on eleven cases proven by renal biopsy. Annals of the Rheumatic Diseases, 19, 126.

JAWS, N.F. (1974) In: Advanced Medicine (Ed by Ledingham, J.G.G.), p. 351. Pitman Medical, London.

Kennedy, A.C., Burton, J.A. \& Allison, M.E.M. (1974) Tuberculosis as a continuing cause of renal amyloidosis. British Medical Journal, 3, 795.

KuHLBACK, B. (1976) Renal biopsy in the diagnosis of amyloidosis. In: Amyloidosis Symposium (Ed by Wezelius, $O$. \& Pasternaik, A.). Academic Press, New York.

KYLE, R.A. \& BAYRD, E.D. (1975) Amyloidosis: review of 236 cases. Medicine. Baltimore, 54, 271.

Lowenstein, J. \& Gallo, G. (1970) Remission of the nephrotic syndrome in renal amyloidosis. New England Journal of Medicine, 282, 128.

Mathur, B.L. \& Jhala, C.I. (1964) Amyloidosis: an emphasis on increasing incidence in India. Indian Journal of Pathology and Bacteriology, 7, 133.

Nakagawa, S. \& Suzue, K. (1964) Amyloidosis in Japan. Pathologia et microbiologia, 27, 850.

Ravid, M., Gafni, J., Sohar, E. \& Missmahl, H.P. (1967). Incidence and origin of non-systemic microdeposits of amyloid. Journal of Clinical Pathology, 20, 15.

Rizvi, S.N.A., Gulati, P.D. \& Vaishnava, H. (1974) Tuberculosis and renal amyloidosis (Letter). British Medical Journal, 4, 657.

Rukavina, J.G., Block, W.G., Jackson, C.E., Falls, H.G., CArey, J.H. \& Curtis, A.C. (1956) Primary systemic amyloidosis. Medicine. Baltimore, 35, 239.

Sohar, E., Gafni, J., Pras, M. \& Heller, H. (1967) Mediterranean fever. A survey of 470 cases and review of the literature. American Journal of Medicine, 43, 227.

Symmers, W. St. C. (1956) Primary amyloidosis. Journal of Clinical Pathology, 9, 187.

Triger, D.R. \& Joekes, A.M. (1973) Renal amyloidosis - a fourteen year follow up. Quarterly Journal of Medicine, 42, 15.

Yoshizumi, M. \& LI, T.G. (1962) Incidence of amyloidosis in tuberculosis. American Review of Respiratory Diseases, 85, 432 . 